\title{
The ubiquitin-specific protease 14 (USP14) is a critical regulator of long-term memory formation
}

\author{
Timothy J. Jarome, ${ }^{1}$ Janine L. Kwapis, ${ }^{1}$ Jada J. Hallengren, ${ }^{2}$ Scott M. Wilson, ${ }^{2}$ \\ and Fred J. Helmstetter ${ }^{1,3}$ \\ ${ }^{1}$ Department of Psychology, University of Wisconsin-Milwaukee, Milwaukee, Wisconsin 53201, USA; ${ }^{2}$ Department \\ of Neurobiology, University of Alabama, Birmingham, Alabama 35294, USA
}

\begin{abstract}
Numerous studies have suggested a role for ubiquitin-proteasome-mediated protein degradation in learning-dependent synaptic plasticity; however, very little is known about how protein degradation is regulated at the level of the proteasome during memory formation. The ubiquitin-specific protease 14 (USP14) is a proteasomal deubiquitinating enzyme that is thought to regulate protein degradation in neurons; however, it is unknown if USP14 is involved in learning-dependent synaptic plasticity. We found that infusion of a USP14 inhibitor into the amygdala impaired long-term memory for a fear conditioning task, suggesting that USP14 is a critical regulator of long-term memory formation in the amygdala.
\end{abstract}

The ubiquitin-proteasome system is a complex network of different ubiquitin ligases that can conjugate the small protein modifier ubiquitin onto individual proteins to target them for degradation (Hegde 2010; Mabb and Ehlers 2010). Once ubiquitinated, target proteins can bind to the $26 \mathrm{~S}$ proteasome and are subsequently deubiquitinated, unfolded, and degraded. Although the selection of proteins to be ubiquitinated is largely regulated by the ubiquitin ligases, the actual degradation of the protein is regulated by a variety of different subunits found on the regulatory particle (19S) of the proteasome. Deubiquitinating enzymes are a class of regulatory proteins that bind the $19 \mathrm{~S}$ complex of the proteasome and they function to regulate the degradation process by removing ubiquitin tags from ubiquitinated proteins bound to the proteasome, which is thought to serve an important role in facilitating substrate entry into the proteasome as well as in maintaining ubiquitin pools.

The ubiquitin-specific protease 14 (USP14) is one of the most extensively studied deubiquitinating enzymes of the proteasome complex and may play a critical role in activity-dependent synaptic plasticity (Kowalski and Juo 2012). For example, loss of USP14 expression results in significant physiological impairments in both the central and peripheral nervous systems in the ataxia $\left(a x^{J}\right)$ mice (Wilson et al. 2002) and these deficits can be largely rescued by transgenic overexpression of USP14 in neurons (Crimmins et al. 2006). Additionally, loss of USP14 results in reduced ubiquitin levels, impaired neurotransmitter release, and increased surface expression of the $\mathrm{GABA}_{\mathrm{A}}$ receptor (Anderson et al. 2005; Chen et al. 2009; Lappe-Siefke et al. 2009; Bhattacharyya et al. 2012), supporting the idea that USP14 is a critical regulator of synaptic plasticity. Interestingly, some studies have shown that USP14 is a negative regulator of ubiquitin-dependent protein turnover in vitro (Lee et al. 2010), suggesting that USP14 could serve a unique function relative to other deubiquitinating enzymes which normally facilitate the degradation process. However, it is currently not known if USP14 plays an important role in long-term memory formation in the mammalian brain.

The formation of long-term fear memories requires new gene transcription and de novo protein synthesis in the amygdala for

\footnotetext{
${ }^{3}$ Corresponding author

E-mail fjh@uwm.edu

Article is online at http://www.learnmem.org/cgi/doi/10.1101/lm.032771.113.
}

their consolidation and long-term storage (Bailey et al. 1999; Schafe and LeDoux 2000). Recently, studies have begun to implicate ubiquitin-proteasome-mediated protein degradation in long-term memory formation (Lopez-Salon et al. 2001; Jarome et al. 2011; Rodriguez-Ortiz et al. 2011; Felsenberg et al. 2012; Pick et al. 2013a,b). However, very few specifics are known about how regulatory factors of the proteasome are involved in longterm memory formation or whether USP14 activity is critical for fear memory formation.

In the present study, we examined whether USP14 activity is critical for the formation of long-term fear memories in the amygdala. The subjects were male Long Evans rats weighing between 300 and $350 \mathrm{~g}$ at the time of arrival (Madison, WI) housed individually in shoebox cages with free access to water and rat chow. All experiments took place during the light portion of a 14:10-h light-dark cycle. All procedures were approved by the University of Wisconsin-Milwaukee Institutional Animal Care and Use Committee and conducted within the ethical guidelines of the National Institutes of Health.

All animals were anesthetized with $2 \%-4 \%$ isoflurane in $100 \% \mathrm{O}_{2}$ and implanted with bilateral stainless-steel 26-gauge cannula aimed at the basolateral nucleus of the amygdala (BLA) using stereotaxic coordinates (AP $-3.0 \mathrm{~mm}, \mathrm{ML} \pm 5.0 \mathrm{~mm}, \mathrm{DV}$ $-7.2 \mathrm{~mm}$ ) relative to bregma. Cannulae were secured to the skull with stainless-steel screws, cyanoacrylate glue, and dental acrylic. Rats were given a recovery period of at least $7 \mathrm{~d}$ before behavioral testing. After completion of testing, animals were killed with an overdose of inhalant isoflurane, transcardially perfused, and injection sites determined as described previously (Jarome et al. 2012).

Auditory fear conditioning and testing were conducted in two sets of four Plexiglas and stainless-steel observation chambers housed in sound-attenuating chambers that have been previously described (Gilmartin et al. 2013). Before testing of each animal, Context A was cleaned with a 5\% ammonium hydroxide solution. Testing to the auditory cue occurred in Context B, which had

(C) 2013 Jarome et al. This article is distributed exclusively by Cold Spring Harbor Laboratory Press for the first 12 months after the full-issue publication date (see http://learnmem.cshlp.org/site/misc/terms.xhtml). After 12 months, it is available under a Creative Commons License (AttributionNonCommercial 3.0 Unported), as described at http://creativecommons. org/licenses/by-nc/3.0/. 
several distinct features relative to Context A, including infrared house lamps, textured floor, and 5\% acetic acid odor.

Five minutes prior to fear conditioning, rats received bilateral infusions $(0.5 \mu \mathrm{L} /$ side $)$ into the amygdala, as described previously (Jarome et al. 2012). The specific USP14 inhibitor IU1 (100 $\mu \mathrm{M}$ or $200 \mu \mathrm{M}$ per side; Sigma) was dissolved in DMSO. Clasto-lactacystin $\beta$-lactone ( $\beta$ lac, $150 \mu \mathrm{M}$; Sigma) was dissolved in $2 \%$ DMSO in distilled $\mathrm{H}_{2} \mathrm{O}$. Animals underwent a two-trial auditory fear conditioning paradigm as described previously (Parsons et al. 2010). The following day, animals were tested to both the auditory and contextual cues in a counterbalanced order (Jarome et al. 2010). The context test consisted of placing the animals in the training context for $8 \mathrm{~min}$ in the absence of shock. For the auditory CS test, animals were placed into novel Context B and after a 60 -sec baseline, received eight white noise (72-dB, 30-sec) presentations (60-sec ITI) in the absence of shock. On the third day the animals were brought back to Context B and given a second CS test.

The activity of each rat was recorded on digital video and the amount of movement determined by frame-by-frame changes in pixels using FreezeScan 2.0 software (CleverSys). Statistical outliers were determined as those samples that fell two or more standard deviations above/below the group mean. Data was analyzed using analysis of variance (ANOVA). Fisher least significant difference (LSD) post hoc tests were used where appropriate.

For in vitro proteasome activity assays, animals $(n=4)$ were overdosed on isoflurane and the amygdala dissected and prepared as described previously (Jarome et al. 2011, 2012). Samples (10 $\mu \mathrm{g})$ were then diluted in double-distilled $\mathrm{H}_{2} \mathrm{O}$ and mixed with reaction buffer (250 mM HEPES, pH 7.5, 5 mM EDTA, 0.5\% NP-40,

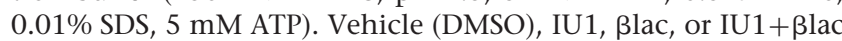
were added to the reactions and incubated for $30 \mathrm{~min}$ at $37^{\circ} \mathrm{C}$. Fluorogenic peptide Suc-LLVY-AMC (Millipore) was then added to the samples to assess proteasome activity $(10 \mu \mathrm{M})$ as described previously (Jarome et al. 2013). The reaction was incubated at $37^{\circ} \mathrm{C}$ for $2 \mathrm{~h}$ and fluorescence monitored every $30 \mathrm{~min}$ at 360 (excitation) $/ 460$ (emission) on a monochromatic plate reader (Synergy H1, Biotek). Protein-free blanks were used and an AMC standard curve was produced.

In our first experiment, we wanted to test if USP14 activity was critical for long-term memory formation in the amygdala
(Fig. 1A,B). Animals were given infusions of IU1 or vehicle (DMSO) prior to fear conditioning. During the training session, all animals acquired the task at a similar rate (Fig. 1C). A mixed variable ANOVA revealed a significant effect for time $\left(F_{(1,27)}=\right.$ $100.269, P<0.001)$ but not $\operatorname{drug}\left(F_{(2,27)}=1.210, P=0.314\right)$, and there was not a time by drug interaction $\left(F_{(2,27)}=2.004\right.$, $P=0.154)$, suggesting that IU1 did not alter the ability of the animals to acquire the task.

The next day, all animals were tested for their responses to the contextual and auditory cues. We found a main effect for drug on the context test $\left(F_{(2,24)}=6.626, P=0.005\right)$ (Fig. 2A). Fisher LSD post hoc tests revealed significant impairments in retention for the training context in animals that received either $100 \mu \mathrm{M}(P=0.026)$ or $200 \mu \mathrm{M}(P=0.002)$ concentrations of IU1 relative to DMSO controls, suggesting that IU1 dosedependently impaired long-term memory for the training context. Interestingly, we did not find a significant effect of the drug on the auditory CS test $\left(F_{(2,27)}=0.280, P=0.758\right)$ (Fig. $\left.2 \mathrm{~B}\right)$, suggesting that USP14 activity was not critical for the consolidation of this type of fear memory in the amygdala. To confirm this, we gave the animals a second CS test the following day (Fig. 2C). Consistent with our previous result, we did not observe any effect of the drug on the second CS test $\left(F_{(2,27)}=0.045, P=\right.$ 0.956). Collectively, these results suggest that USP14 activity is critical for the long-term consolidation of contextual, but not auditory, fear memories in the amygdala.

Since USP14 is a regulatory subunit of the proteasome, we next wanted to know if IU1-induced memory impairments were due to altered proteasome activity in the amygdala (Fig. 3). To test this, we inhibited USP14 activity in amygdala lysates and measured proteasome activity using an in vitro proteasome activity assay. As a control, we also incubated samples with ßlac, a selective inhibitor of the catalytic subunits of the proteasome. We found main effects for time $\left(F_{(1,21)}=20.795, P<0.001\right)$ and drug $\left(F_{(6,21)}=3.053, P=0.026\right)$ and a time by drug interaction $\left(F_{(6,21)}=2.678, P=0.043\right)$. Fisher LSD post hoc tests revealed a significant reduction in proteasome activity in all $\beta$ lac groups (all $P$ 's $<0.05$ ) from minutes 30 to 120 (scans 2-5); however, the IU1 groups never differed from DMSO controls at any time throughout the incubation. These results suggest that while blocking USP14 activity with IU1 impaired long-term memory formation in the amygdala, this effect was largely independent of changes in the catalytic activity of the proteasome.

To summarize, we found that transient inhibition of the proteasome deubiquitinating enzyme USP14 in the amygdala impairs long-term memory for contextual, but not auditory, fear memories. Additionally, USP14 inhibition did not alter proteasome catalytic activity in the amygdala, suggesting that USP14 likely regulates memory consolidation through a mechanism independent of proteasome activity. Collectively, these results suggest that USP14 activity is critical for long-term memory formation in the amygdala.

We found that inhibiting the activity of the proteasome regulatory subunit USP14 in the amygdala impaired longterm memory formation. Inhibiting USP14 with IU1 enhances the degradation of proteasome substrates both in vitro and in vivo, which is likely through 

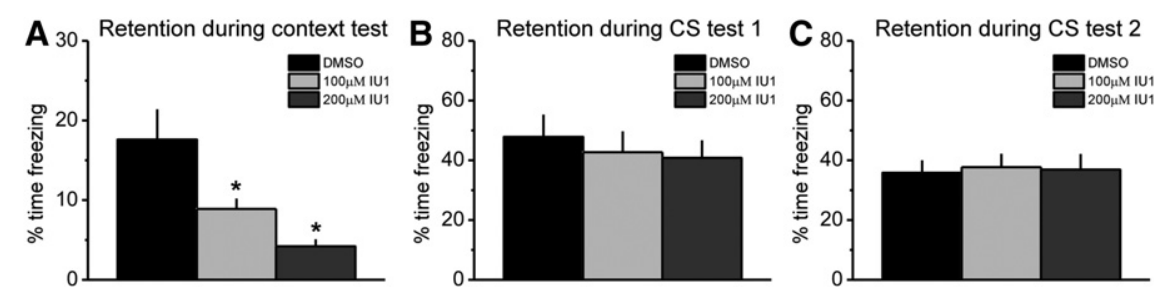

Figure 2. Inhibition of USP14 activity in the amygdala impairs the consolidation of contextual but not auditory fear memories. (A) Pre-training IU1 infusions dose-dependently impaired long-term memory retention for the training context relative to DMSO controls. $(B, C)$ Pre-training IU1 infusions did not impair long-term memory for the auditory CS when tested $1 \mathrm{~d}(B)$ and $2 \mathrm{~d}(C)$ after the training. $\left.{ }^{*}\right)$ $P<0.05$.

a mechanism independent of changes in proteasome activity (Koulich et al. 2008; Lee et al. 2010); however, it has never been tested if IU1 alters proteasome activity in vivo. Additionally, USP14 can alter 20S proteasome activity by changing the gating of the $20 \mathrm{~S}$ proteasome, but it is unknown if IU1 stimulates gate opening in vivo (Peth et al. 2009). Finally, inhibiting proteasome catalytic activity can alter the activity of USP14 on the proteasome, suggesting a coordinated regulation between these two functions on the proteasomes (Borodovsky et al. 2001). Thus it is possible that IU1-induced memory impairments could be due to altered proteasome activity in the amygdala which resulted in a weaker memory trace. To test if IU1 altered the catalytic activity of the 20 S proteasome, we inhibited USP14 activity with IU1 and measured proteasome activity in the amygdala. We found that inhibiting USP14 activity in the amygdala with concentrations of IU1 that impaired long-term memory formation did not alter proteasome catalytic activity, even when the concentration was 2-4 times higher than that needed to impair memory retention. Since USP14 inhibition did not alter proteasome activity in the amygdala, this suggests that it is unlikely that the impairments in longterm memory from IU1 infusions were due to altered proteasome catalytic activity. However, USP14 can regulate substrate turnover by the proteasome, suggesting that IU1 altered the degradation of a specific number of substrates. While we could not test changes in the degradation of specific proteasome substrates in the present study, these results do support a critical role for USP14 activity in memory formation in mammals.

Although evidence suggests that inhibition of proteasome activity impairs long-term memory (Lopez-Salon et al. 2001; Artinian et al. 2008; Jarome et al. 2011), other studies have found that proteasome inhibitors enhance (Yeh et al. 2006; Felsenberg et al. 2012) or have no effect (Lee et al. 2008) on memory. Additionally, similar conflicting results have been reported with the proposed cellular analog of memory, long-term potentiation (Fonseca et al. 2006; Dong et al. 2008). Collectively, these results suggest that while ubiquitin-proteasome-mediated proteolysis is critical for synaptic plasticity and long-term memory formation, the exact function of this process can vary depending on brain region and the substrates being targeted for degradation by the proteasome. Here, we add to this growing literature by showing that the proteasome deubiquitinating enzyme USP14 is critical for memory formation. Considering that USP14 is one of the proteins in the ubiquitin-proteasome system that controls substrate degradation by the proteasome, determining what brain regions and behavioral tasks USP14 is involved in will be important to improve our understanding of the role of protein degradation in synaptic plasticity and memory formation.

Very little is known about how protein degradation is regulated during the memory consolidation period. Previously, it has been shown that deubiquitinating enzyme Ap-Uch is critical for the induction of long-term facilitation in Aplysia (Hegde et al. 1997), suggesting that deubiquitinating activity is critical for synaptic plasticity (Chain et al. 1995). However, genetic loss of the deubiquitinating enzyme Uchl3 in mice did not alter longterm memory for contextual or auditory fear conditioning, nor did it impair longterm potentiation (LTP) in the hippocampus (Wood et al. 2005), suggesting that deubiquitinating activity may not be necessary for fear memory formation in the brain. Consistent with this, while a knockout of UCH-L1 results in a variety of developmental impairments in mice, it does not alter synaptic plasticity in the hippocampus (Walters et al. 2008), though other studies have suggested a potential role for UCH-L1 in hippocampal LTP (Kabuta et al. 2008). In the present study, we found that transiently inhibiting the deubiquitinating enzyme USP14 impaired longterm memory for a fear conditioning task. In combination with previous studies demonstrating a role for USP14 in synaptic plasticity (Wilson et al. 2002; Walters et al. 2008), these results suggest that USP14 may be a critical deubiquitinating enzyme regulating synaptic plasticity and long-term memory formation in the mammalian brain.

One interesting finding from our study is that IU1 infusions selectively impaired long-term memory for the contextual but not the auditory cue. Generally, pharmacological manipulations of the amygdala result in long-term memory impairments for both auditory and contextual cues (Jarome et al. 2011), suggesting that postsynaptic plasticity in the amygdala underlies the longterm storage of both auditory and contextual fear memories (Johansen et al. 2011; Jarome and Helmstetter 2013). Although it is unclear why contextual fear memories were selectively affected by IU1 in the present experiment, one potential explanation is that USP14 acts to regulate presynaptic plasticity between the amygdala and hippocampus. For example, mice deficient in USP14 have a loss of paired pulse facilitation but normal LTP in the hippocampus (Wilson et al. 2002). Consistent with this, USP14 has been shown to be required to maintain synaptic vesicle pools to sustain synaptic transmission (Bhattacharyya et al. 2012). Thus it is possible that USP14 regulates the consolidation of contextual fear memory through altered plasticity at amygdala inputs to the hippocampus. Indeed, the amygdala has been shown to

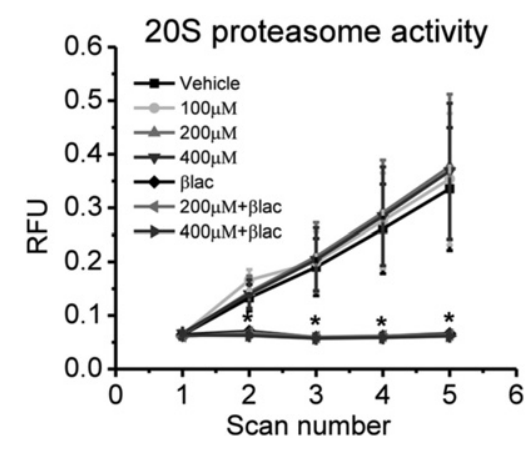

Figure 3. Inhibition of USP14 activity does not alter proteasome catalytic activity in the amygdala. In vitro proteasome activity was measured in amygdala lysates collected from naive animals $(n=4)$. Samples were incubated in DMSO, IU1 $(100 \mu \mathrm{M}, 200 \mu \mathrm{M}$, and $400 \mu \mathrm{M})$, Blac (150 $\mu \mathrm{M})$, and IU1 + Blac $(200 \mu \mathrm{M}+150 \mu \mathrm{M}$ and $400 \mu \mathrm{M}+150 \mu \mathrm{M})$ solutions for $30 \mathrm{~min}$ prior to the addition of the fluorogenic substrate. IU1 infusions did not alter the time-dependent degradation of the fluorogenic substrate. $(*) P<0.05$. 
regulate plasticity in the hippocampus during the consolidation of a contextual fear memory (Huff et al. 2006), suggesting that USP14 could potentially regulate this systems level consolidation process between the amygdala and hippocampus. This interpretation is consistent with our result showing that the IU1-induced memory impairments occurred independently of alterations in proteasome catalytic activity since if proteasome activity was altered by USP14 inhibition, we would have expected impairments in memory retention for both the auditory and contextual cues (Jarome et al. 2011). Additionally, since USP14 may have substrate specificity (Hu et al. 2005; Lee et al. 2010), it is possible that USP14 is acting on a limited number of substrates during the memory consolidation process. This would suggest that blocking USP14 activity would only partially replicate effects seen by proteasome inhibition and could explain the selective context effect. Also, since IU1 is likely accelerating substrate degradation, it is possible that the memory impairments observed from IU1 infusion are due to the enhanced degradation of specific proteins that would normally not be degraded by the proteasome during memory formation. Furthermore, it is possible that IU1 is disrupting memory through a process that is not linked to protein degradation. Consistent with this, ubiquitin signaling can regulate learning-dependent synaptic plasticity independent of protein degradation (Pavlopoulos et al. 2011). Since USP14 regulates the length of the ubiquitin chain on a substrate, it is possible that USP14 regulates memory formation by trimming ubiquitin chains and targeting substrates for other nonproteolytic functions. Future studies should aim to more precisely dissect these potential functions of USP14 in the regulation of learning-dependent synaptic plasticity in the amygdala.

In conclusion, our data suggest that USP14 specifically regulates the consolidation of contextual, but not auditory, fear memories. Additionally, USP14-dependent memory formation is independent of changes in proteasome catalytic activity, suggesting that USP14 regulates memory formation through a process independent of changes in proteasome activity. These results show for the first time that USP14 is critical for long-term memory formation in mammals and add to the growing body of evidence implicating the ubiquitin-proteasome system in long-term memory formation.

\section{Acknowledgments}

This work was supported by National Institutes of Health grants MH06558 (F.J.H.), MH088125 (T.J.J.), NS047533 and NS074456 (S.M.W.), and the American Psychological Foundation (T.J.J.).

\section{References}

Anderson C, Crimmins S, Wilson JA, Korbel GA, Ploegh HL, Wilson SM. 2005. Loss of Usp14 results in reduced levels of ubiquitin in ataxia mice. J Neurochem 95: 724-731.

Artinian J, McGauran AM, De Jaeger X, Mouledous L, Frances B, Roullet P. 2008. Protein degradation, as with protein synthesis, is required during not only long-term spatial memory consolidation but also reconsolidation. Eur J Neurosci 27: 3009-3019.

Bailey DJ, Kim JJ, Sun W, Thompson RF, Helmstetter FJ. 1999. Acquisition of fear conditioning in rats requires the synthesis of mRNA in the amygdala. Behav Neurosci 113: 276-282.

Bhattacharyya BJ, Wilson SM, Jung H, Miller RJ. 2012. Altered neurotransmitter release machinery in mice deficient for the deubiquitinating enzyme Usp14. Am J Physiol Cell Physiol 302: C698-C708.

Borodovsky A, Kessler BM, Casagrande R, Overkleeft HS, Wilkinson KD, Ploegh HL. 2001. A novel active site-directed probe specific for deubiquitylating enzymes reveals proteasome association of USP14. EMBO J 20: 5187-5196.

Chain DG, Hegde AN, Yamamoto N, Liu-Marsh B, Schwartz JH. 1995. Persistent activation of cAMP-dependent protein kinase by regulated proteolysis suggests a neuron-specific function of the ubiquitin system in Aplysia. J Neurosci 15: 7592-7603.

Chen PC, Qin LN, Li XM, Walters BJ, Wilson JA, Mei L, Wilson SM. 2009. The proteasome-associated deubiquitinating enzyme Usp14 is essential for the maintenance of synaptic ubiquitin levels and the development of neuromuscular junctions. J Neurosci 29: 10909-10919.

Crimmins S, Jin Y, Wheeler C, Huffman AK, Chapman C, Dobrunz LE, Levey A, Roth KA, Wilson JA, Wilson SM. 2006. Transgenic rescue of ataxia mice with neuronal-specific expression of ubiquitin-specific protease 14. J Neurosci 26: 11423-11431.

Dong C, Upadhya SC, Ding L, Smith TK, Hegde AN. 2008. Proteasome inhibition enhances the induction and impairs the maintenance of late-phase long-term potentiation. Learn Mem 15: 335-347.

Felsenberg J, Dombrowski V, Eisenhardt D. 2012. A role of protein degradation in memory consolidation after initial learning and extinction learning in the honeybee (Apis mellifera). Learn Mem 19: $470-477$.

Fonseca R, Vabulas RM, Hartl FU, Bonhoeffer T, Nagerl UV. 2006. A balance of protein synthesis and proteasome-dependent degradation determines the maintenance of LTP. Neuron 52: 239-245.

Gilmartin MR, Kwapis JL, Helmstetter FJ. 2013. NR2A- and NR2B-containing NMDA receptors in the prelimbic medial prefrontal cortex differentially mediate trace, delay, and contextual fear conditioning. Learn Mem 20: 290-294.

Hegde AN. 2010. The ubiquitin-proteasome pathway and synaptic plasticity. Learn Mem 17: 314-327.

Hegde AN, Inokuchi K, Pei W, Casadio A, Ghirardi M, Chain DG, Martin KC, Kandel ER, Schwartz JH. 1997. Ubiquitin C-terminal hydrolase is an immediate-early gene essential for long-term facilitation in Aplysia. Cell 89: 115-126.

Hu M, Li P, Song L, Jeffrey PD, Chenova TA, Wilkinson KD, Cohen RE, Shi Y. 2005. Structure and mechanisms of the proteasome-associated deubiquitinating enzyme USP14. EMBO J 24: 3747-3756.

Huff NC, Frank M, Wright-Hardesty K, Sprunger D, Matus-Amat P, Higgins E, Rudy JW. 2006. Amygdala regulation of immediate-early gene expression in the hippocampus induced by contextual fear conditioning. J Neurosci 26: 1616-1623.

Jarome TJ, Helmstetter FJ. 2013. The ubiquitin-proteasome system as a critical regulator of synaptic plasticity and long-term memory formation. Neurobiol Learn Mem 105: 107-116.

Jarome TJ, Kwapis JL, Nye SH, Helmstetter FJ. 2010. Introgression of Brown Norway chromosome 1 onto the fawn hooded hypertensive background rescues long-term fear memory deficits. Behav Genet 40: $85-92$.

Jarome TJ, Werner CT, Kwapis JL, Helmstetter FJ. 2011. Activity dependent protein degradation is critical for the formation and stability of fear memory in the amygdala. PLoS One 6: e24349.

Jarome TJ, Kwapis JL, Werner CT, Parsons RG, Gafford GM, Helmstetter FJ. 2012. The timing of multiple retrieval events can alter GluR1 phosphorylation and the requirement for protein synthesis in fear memory reconsolidation. Learn Mem 19: 300-306.

Jarome TJ, Kwapis JL, Ruenzel WL, Helmstetter FJ. 2013. CaMKII, but not protein kinase A, regulates Rpt6 phosphorylation and proteasome activity during the formation of long-term memories. Front Behav Neurosci 7: 115.

Johansen JP, Cain CK, Ostroff LE, LeDoux JE. 2011. Molecular mechanisms of fear learning and memory. Cell 147: 509-524.

Kabuta T, Setsuie R, Mitsui T, Kinugawa A, Sakurai M, Aoki S, Uchida K, Wada K. 2008. Aberrant molecular properties shared by familial Parkinson's disease-associated mutant UCH-L1 and carbonyl-modified UCH-L1. Hum Mol Genet 17: 1482-1496.

Koulich E, Li X, DeMartino GN. 2008. Relative structural and functional roles of multiple deubiquitylating proteins associated with mammalian 26S proteasome. Mol Biol Cell 19: 1072-1082.

Kowalski JR, Juo P. 2012. The role of deubiquitinating enzymes in synaptic function and nervous system diseases. Neural Plast 2012: 892749.

Lappe-Siefke C, Loebrich S, Hevers W, Waidmann OB, Schweizer M, Fehr S, Fritschy JM, Dikic I, Eilers J, Wilson SM, et al. 2009. The ataxia (axJ) mutation causes abnormal GABAA receptor turnover in mice. PLoS Genet 5: e1000631.

Lee SH, Choi JH, Lee N, Lee HR, Kim JI, Yu NK, Choi SL, Kim H, Kaang BK. 2008. Synaptic protein degradation underlies destabilization of retrieved fear memory. Science 319: 1253-1256.

Lee BH, Lee MJ, Park S, Oh DC, Elsasser S, Chen PC, Gartner C, Dimova N, Hanna J, Gygi SP, et al. 2010. Enhancement of proteasome activity by a small-molecule inhibitor of USP14. Nature 467: 179-184.

Lopez-Salon M, Alonso M, Vianna MR, Viola H, Mello e Souza T, Izquierdo I, Pasquini JM, Medina JH. 2001. The ubiquitin-proteasome cascade is required for mammalian long-term memory formation. Eur J Neurosci 14: 1820-1826. 
Mabb AM, Ehlers MD. 2010. Ubiquitination in postsynaptic function and plasticity. Апnи Rev Cell Dev Biol 26: 179-210.

Parsons RG, Gafford GM, Helmstetter FJ. 2010. Regulation of extinction-related plasticity by opioid receptors in the ventrolateral periaqueductal gray matter. Front Behav Neurosci 4: 44.

Pavlopoulos E, Trifilieff P, Chevaleyre V, Fioriti L, Zairis S, Pagano A, Malleret G, Kandel ER. 2011. Neuralized1 activates CPEB3: A function for nonproteolytic ubiquitin in synaptic plasticity and memory storage. Cell 147: 1369-1383.

Paxinos G, Watson C. 2007. The rat brain in stereotaxic coordinates. Academic Press, Amsterdam, The Netherlands.

Peth A, Besche HC, Goldberg AL. 2009. Ubiquitinated proteins activate the proteasome by binding to Usp14/Ubp6, which causes $20 \mathrm{~S}$ gate opening. Mol Cell 36: 794-804.

Pick JE, Malumbres M, Klann E. 2013a. The E3 ligase APC/C-Cdh1 is required for associative fear memory and long-term potentiation in the amygdala of adult mice. Learn Mem 20: 11-20.

Pick JE, Wang L, Mayfield JE, Klann E. 2013b. Neuronal expression of the ubiquitin E3 ligase APC/C-Cdh1 during development is required for long-term potentiation, behavioral flexibility, and extinction. Neurobiol Learn Mem 100: 25-31.

Rodriguez-Ortiz CJ, Balderas I, Saucedo-Alquicira F, Cruz-Castaneda P, Bermudez-Rattoni F. 2011. Long-term aversive taste memory requires insular and amygdala protein degradation. Neurobiol Learn Mem 95: $311-315$

Schafe GE, LeDoux JE. 2000. Memory consolidation of auditory pavlovian fear conditioning requires protein synthesis and protein kinase $\mathrm{A}$ in the amygdala. J Neurosci 20: RC96.

Walters BJ, Campbell SL, Chen PC, Taylor AP, Schroeder DG, Dobrunz LE, Artavanis-Tsakonas K, Ploegh HL, Wilson JA, Cox GA, et al. 2008. Differential effects of Usp14 and Uch-L1 on the ubiquitin proteasome system and synaptic activity. Mol Cell Neurosci 39: $539-548$.

Wilson SM, Bhattacharyya B, Rachel RA, Coppola V, Tessarollo L, Householder DB, Fletcher CF, Miller RJ, Copeland NG, Jenkins NA. 2002. Synaptic defects in ataxia mice result from a mutation in Usp14, encoding a ubiquitin-specific protease. Nat Genet 32: 420-425.

Wood MA, Kaplan MP, Brensinger CM, Guo W, Abel T. 2005. Ubiquitin C-terminal hydrolase L3 (Uchl3) is involved in working memory. Hippocampus 15: 610-621.

Yeh SH, Mao SC, Lin HC, Gean PW. 2006. Synaptic expression of glutamate receptor after encoding of fear memory in the rat amygdala. Mol Pharmacol 69: 299-308.

Received August 7, 2013; accepted in revised form October 14, 2013. 


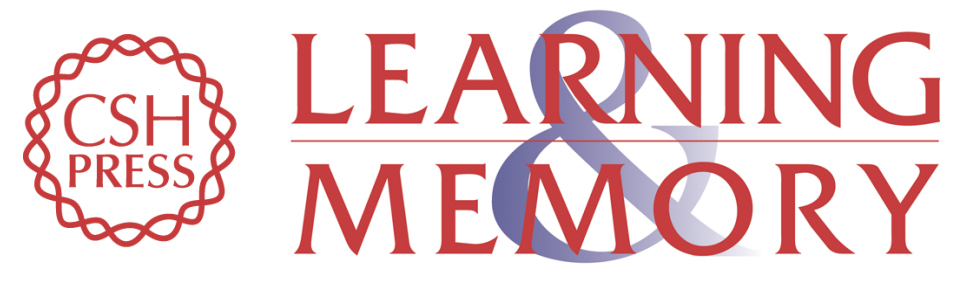

\section{The ubiquitin-specific protease 14 (USP14) is a critical regulator of long-term memory formation}

Timothy J. Jarome, Janine L. Kwapis, Jada J. Hallengren, et al.

Learn. Mem. 2014, 21:

Access the most recent version at doi:10.1101/Im.032771.113

References This article cites 41 articles, 15 of which can be accessed free at: http://learnmem.cshlp.org/content/21/1/9.full.html\#ref-list-1

Creative This article is distributed exclusively by Cold Spring Harbor Laboratory Press for the Commons License first 12 months after the full-issue publication date (see http://learnmem.cshlp.org/site/misc/terms.xhtml). After 12 months, it is available under a Creative Commons License (Attribution-NonCommercial 3.0 Unported), as described at http://creativecommons.org/licenses/by-nc/3.0/.

Email Alerting Receive free email alerts when new articles cite this article - sign up in the box at the Service top right corner of the article or click here. 